\title{
Epidemiological Analysis and Time Prediction Models of Coronavirus (COVID-19/SARS-CoV-2) Spread in Selected Epicentres around the World: Nigeria as a Case Study
}

Favour Deborah Adaugo Onyelowe ${ }^{1}$, Kennedy Onyelowe $^{2}$

\author{
${ }^{1}$ Ebonyi State University \\ P. M. B. 053, Abakaliki, Nigeria \\ ${ }^{2}$ Kampala International University \\ Box 20000, Ggaba Road, Kansanga, Kampala, Uganda
}

DOI: $10.22178 /$ pos.60-4

LCC Subject Category: WC500-593

Received 26.06.2020

Accepted 28.07.2020

Published online 31.07.2020

Corresponding Author:

Kennedy Onyelowe

adaugofavour3@gmail.com

(C) 2020 The Authors. This article is licensed under a Creative Commons

Attribution 4.0 License @) (1)
Abstract. The spread of coronavirus disease (COVID-19/SARS-CoV-2) in Nigeria from index to community cases is becoming alarming that what the future holds should be brought to bear. An analytical study and time prediction model have been conducted on the epidemiological spread of coronavirus (COVID-19/SARS-CoV-2) with data collected from records of selected epicentres in Nigeria. The data was collected between March 1 and May 31, 2020. It can be shown that the highest daily infection in March was recorded on the 28th with 32 infections while the highest fatality rate was recorded on 24th with a rate of $2.3 \%$ and recorded daily infection of 10 . As at the $31 \mathrm{st}$, a total number of 139 confirmed cases were recorded in Nigeria with a fatality and discharge rates of 1.4 and $6.5 \%$ respectively. It can be deduced that the highest daily infection in Nigeria in April was recorded on 30th, with daily infection of 204 confirmed cases. The highest discharge rate of $34.4 \%$ was recorded on 16 th, with a fatality rate of $2.9 \%$ while the highest fatality rate of April was 3.5\% recorded on 18th, which has a discharge rate of $30.6 \%$ and a daily infection record of 49 . As of April 30, 2020, Nigeria had recorded a total of 1932 confirmed cases with 58 deaths. It can also be deduced that the highest daily infection in Nigeria in May was recorded on 30th, with daily infection of 553 confirmed cases. It can also be observed that the highest discharge and fatality rates for May 2020 are $29.6 \%$ and $3.6 \%$ recorded on 31 st and 2 nd respectively. As of May 31,2020 , the total infection stood at 10162 confirmed cases and there seems to be a continuing upward trajectory for the situation under investigation. It can also be observed that the rate of discharged cases continued to surpass those of the fatality for the months of investigation. No doubts that the COVID-19/SARS-CoV-2 was first recorded in the Ogun State of Nigeria, but Lagos state has surpassed both the daily infections and the cumulative infections for the country. With collected data, MLR simple linear regression extension was used to estimate an outcome or target variable based on two or more independent variables. The variables which are the three months data collected from daily infections, totally confirmed case, total deaths and total discharged cases between March 1, 2020, and May 31, 2020, were used to propose regression equations for the prediction of the cases under study for anytime period.

Keywords: Coronavirus; Time Prediction Model; Epidemiological Spread; Epicentre of Viral Infection; Confirmed Cases; Discharged Cases; Intravascular Coagulation; Biomedicine; Pneumonia; Symptomatic Infections; Asymptomatic Infections; Community Infections. 


\section{INTRODUCTION}

Coronavirus disease is a potentially severe acute respiratory infection caused by severe acute respiratory syndrome coronavirus 2 (SARS-CoV-2). According to WHO, 44 cases of pneumonia of unknown microbial etiology entangled with Wuhan city, Hubei province china on 31 December 2019 $[12,5]$. According to [2] $87 \%$ of confirmed cases were aged 30 to 79 years, $1 \%$ were aged 80 years or older. Approximately $51 \%$ of patients were male and $49 \%$ were female. In the US older patients aged greater than or equal to 65 years accounted for $31 \%$ of all cases, $45 \%$ of hospitalizations, $53 \%$ of intensive care unit admissions and $80 \%$ of deaths, with the highest inci- dence of severe outcomes in patients aged greater than or equal to 85 years [4]. According to findings, weather conditions may influence the transmission of COVID-19, with cold and dry conditions appearing to increase transmission, and warm and humid conditions reducing the risk of cases and deaths in some countries [11]. Most common symptoms of COVID-19 include fever, cough, dyspnea, myalgia, fatigue, altered sense of taste/smell, while less common symptoms include sore throat, confusion, dizziness, headache, rhinorrhea, or nasal congestion, hemoptysis, chest pain, conjunctivitis, cutaneous manifestations [14] (Figure 1).

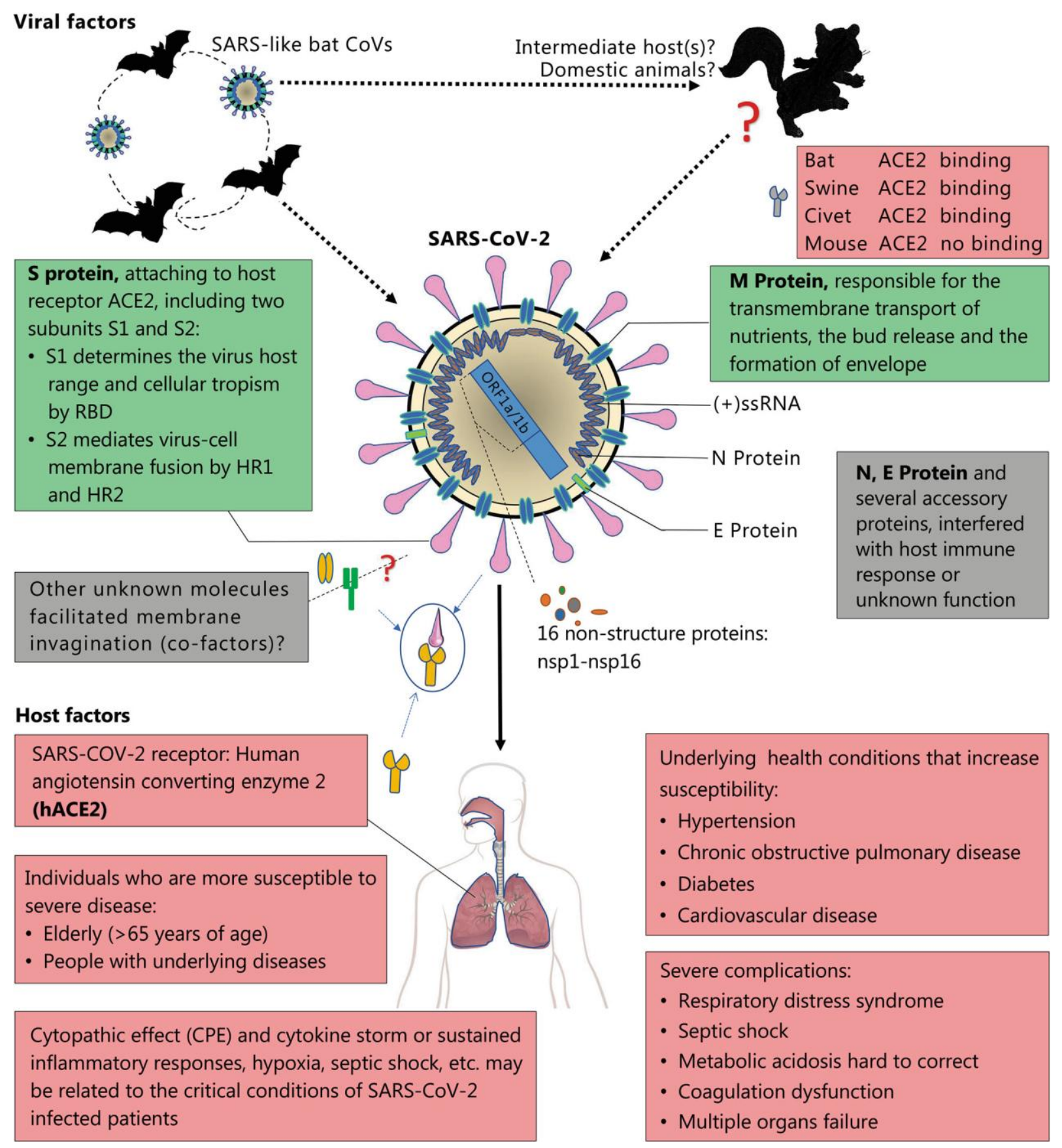

Figure 1 - COVID-19/SARS-CoV-2 origin, infectious and effect factors on humans [8] 
Approximately $90 \%$ of patients present with more than one symptom, and $15 \%$ of patients present with fever, cough, and dyspnea. On January 7, a novel coronavirus was identified by the Chinese centre of Disease Control and Prevention (CDC) from the throat swab sample of a patient and was subsequently named 2019-nCoV by WHO [12, 5]. According to [8], COVID-19 can cause multiple system infections in respiratory tract infections in humans, such as Severe Acute Respiratory Syndrome (SARS) and Middle East Respiratory Syndrome (MERS). The following research was carried out in china on patients with SARS-CoV-2 according to age. $10 \%$ of these patients were less than or equal to 39 years old, $22 \%$ of these patients were 40-49 years old, $30 \%$ - 50-59 years old, $22 \%$ - 60-69 years old, $15 \%$ - greater than or equal to 70 years old. The same research was carried out according to sex. There were $32 \%$ of female patients and $68 \%$ of male patients.

Epicentres/severely affected countries on the epidemiological spread of COVID-19/SARS-CoV-2 across continents. According to [10] between late February and the early march of 2020, the individual data of laboratory-confirmed cases of COVID-19 were retrieved from 10728 publicly available reports released by the health authorities of and outside china and from 1790 publications identified in PubMed and CNKI. According to [13], Europe has become the new epicentre of the COVID-19 pandemic. Italy was initially the county hit the hardest by far Spain, the Netherlands and other followed. France and Germany had experienced the first importation of cases already in January. On 10 March, the total number of fatalities in Italy exceeded 3,000, topping the total number of reported fatalities in china. Outside Europe, Iran faced a rapid surge of COVID-19 followed by the exportation of cases mostly to countries in the Middle East [3]. The United States in North America and Europe in the United Kingdom emerged as new epicentre with 124,655 cases plus 1,019 fatalities respectively, reported by 29 March [6]. Recently increasing case numbers have also been seen in Africa and Asian countries outside China [9].

The novel coronavirus has two modes of transmission which includes droplets with a particle size of 5-10 $\mu \mathrm{m}$ and transmissible distance of $<3$ $\mathrm{ft}$. SARS-CoV-2 survives on surface materials like copper with a half-life of 1 hour and a total time of detectability of 8 hours, cardboard with a halflife of 3 hours and a total time of detectability of
48 hours, and plastic with a half-life of 7 hours and a total time of detectability of 72 hours. SARS (Severe Acute Respiratory Syndrome) started onset November 2002 [9]. Its last known case was 2004. MERS (Middle East Respiratory Syndrome) started onset 2012 in Saudi Arabia. Saudi Arabia outbreak in 2004 recorded 402 cases and $27 \%$ mortality. South Korea outbreak in 2015 recorded 105 cases and 17\% mortality. United States outbreak recorded 2 cases in 2014, including health care workers travelling from Saudi Arabia [15].

COVID-19 Timeline showed that from December 31-January 3, 2020, 44 cases of pneumonia of unknown cause was reported in Wuhan $[3,13]$. On January 7, 2020, new coronavirus was identified. On January 13, 2020: Thailand, on January 15, 2020: Japan, on January 20, 2020: South Korea, on January 23, 2020: the United States and on April 4, 2020, worldwide cases surpassed 1 million [10].

The novel COVID-19 was declared a global pandemic by the World Health Organization (WHO) on the 11 March 2020. The WHO has reported an incubation period for COVID-19 between 2 and 10 days. However, according to research incubation period can last for longer than two weeks. However, according to $[3,1]$, cases reported in china according to location and patients include; Mainland china - 364 (72\%), Beijing 133 (26\%), Shaanxi - 87 (17\%), Hubei - 41 (8\%), Tianjin - 22 (4\%), Yunnan - 19 (4\%). And the mortality rate around the world vary by country as of the first week of April 2020 as follows; China - $4.0 \%$, South Korea - $1.8 \%$, Italy $12.5 \%$, Spain - $9.7 \%$, Iran - $6.2 \%$, United States - $3.2 \%$, worldwide - $5.6 \%$. As of April 7th 2020, $1,353,361$ confirmed cases worldwide, 79,235 confirmed deaths, 212 counties, areas or territories with cases.

Epicentres/severely affected states on the epidemiological spread of COVID-19/SARS-CoV-2 Nigeria. The report has shown that coronavirus is one of the major pathogens that mainly targets the human respiratory system [7]. The first case of COVID-19 was reported in December 2019. From December 18, 2019, through December 29, 2019, five patients were hospitalized with acute respiratory distress syndrome. By January 2, 2020, 41 admitted hospital patients had been identified as having laboratory-confirmed COVID-19 infections, less than half of the patients had underlying diseases including diabetes, hypertension, 
and cardiovascular diseases. Different bodies including the WHO and the US Centres for Disease Control and Preventions (CDC) have issued advice on preventing further spread of COVID-19. They have advised that travel to high-risk areas should be avoided, and contact with symptomatic patients should also be avoided. Basic hand hygiene measures are also recommended including frequent hand washing. The SARS-CoV-2 possesses a single strand, positive-sense RNA genome ranging from 26-32 kilobases in length. Coronavirus has been identified in various mammals including camels, bats, masked palm civets, mice, dogs and cats. The COVID-19/SARSCoV-2 was first recorded in the Ogun State of Nigeria, but Lagos state has surpassed both the daily infections and the cumulative infections for the country. On May 30, 2020, Lagos state recorded a daily total of 378 confirmed cases and Kano state has continued to follow in the rate at which cases are confirmed in Nigeria and followed by the other 8 states. Also beyond these 10 states in view, the tide is changing towards the south-south and south-east regions of Nigeria and this demands urgent study.

\section{METHODOLOGY}

Data Collection. The data for this work was collected using sampling method and released information from the WHO, CDC and NCDC on daily monitoring of the recorded cases of events across the world and particularly Nigeria. The collation of the data took three months spanning between
March 1 and May 31, 2020. The cumulative daily cases of infection, discharged and deaths were collated and the rates of discharge and deaths were computed by common calculation. A literature search was also incorporated and lastly, a graphical analysis of the epidemiological spread of the COVID-19/SARS-CoV-2 was conducted.

Model Development and Statistical Hypothesis. MLR is a simple linear regression extension used to estimate an outcome or target variable based on two or more independent variables. The expected parameter to be estimated is termed the dependent or outcome variable, which is total case discharged, total deaths and total case confirmed within a study period. The variables or factors utilized to produce the estimation results are termed the predictor/independent/criterion variables or explanatory variables, which are the three months data collected from daily infections, totally confirmed case, total deaths and total discharged cases between March 1, 2020, and May 31,2020 . MLR aids in the determination of the variance explained (overall fit) of the model in terms of respective contributions of each explanatory parameter to the total variance explained. It is also used to assess the relationship strength which exists between two or more variables and its respective target variables.

The descriptive statistics of the data utilized for the model development which consist of epidemiological statistics of COVID-19/SARS-CoV-2 cases in Nigeria for three months duration are presented in Table 1.

Table 1 - Statistical parameters of data sets for the model development

\begin{tabular}{|l|r|r|r|r|r|r|r|}
\hline Model Variables & \multicolumn{1}{|c|}{ SE } & \multicolumn{1}{c|}{ Mean } & \multicolumn{1}{c|}{ SD } & Range & SV & Minimum & Maximum \\
\hline Duration & 2.78 & 46.50 & 26.70 & 91 & 713.00 & 1 & 92 \\
\hline Daily infections & 13.43 & 110.61 & 128.84 & 553 & 16601.03 & 0 & 553 \\
\hline \% discharge & 1.12 & 16.26 & 10.71 & 34.4 & 114.80 & 0 & 34.4 \\
\hline Total discharged & 86.52 & 541.86 & 829.85 & 3007 & 688659.22 & 0 & 3007 \\
\hline Total deaths & 9.17 & 65.90 & 87.96 & 287 & 7737.47 & 0 & 287 \\
\hline Total confirmed cases & 309.33 & 2188.36 & 2966.98 & 10161 & 8802971.75 & 1 & 10162 \\
\hline
\end{tabular}

\section{Statistical Hypothesis:}

Null Hypothesis: all the parameters of predictors are not significantly different from zeros which implies that the model is not statistically significant. This is expressed mathematically in Formula 1:

$$
H_{0}: \beta_{1}=\beta_{2} \ldots \beta_{n}=0
$$

Alternate Hypothesis: at least one predictor parameter is significantly different from zero that is the model is statistically significant. This is expressed mathematically in Formula 2:

$$
H_{1}: \beta_{1} \neq \beta_{2} \ldots \beta_{n} \neq 0
$$




\section{RESULTS AND DISCUSSION}

Epidemiological timeline of COVID-19/SARS-CoV-2 spread in Nigeria from March 1, 2020 to May 31, 2020. Tables 2-3 and Figures 2-7 represent the epidemiological timeline of COVID-19/SARSCoV-2 spread in Nigeria from March 1, 2020, to

Table 2 - March 2020 epidemiological statistics of COVID-19/SARS-CoV-2 cases in Nigeria

\begin{tabular}{|c|c|c|c|c|c|c|}
\hline Date & Total confirmed cases & Daily infections & Total discharged & $\%$ discharge & Total deaths & $\%$ deaths \\
\hline 1 & 1 & 1 & 0 & 0 & 0 & 0 \\
\hline 2 & 1 & 0 & 0 & 0 & 0 & 0 \\
\hline 3 & 1 & 0 & 0 & 0 & 0 & 0 \\
\hline 4 & 1 & 0 & 0 & 0 & 0 & 0 \\
\hline 5 & 1 & 0 & 0 & 0 & 0 & 0 \\
\hline 6 & 1 & 0 & 0 & 0 & 0 & 0 \\
\hline 7 & 1 & 0 & 0 & 0 & 0 & 0 \\
\hline 8 & 1 & 0 & 0 & 0 & 0 & 0 \\
\hline 9 & 1 & 0 & 0 & 0 & 0 & 0 \\
\hline 10 & 2 & 1 & 0 & 0 & 0 & 0 \\
\hline 11 & 2 & 0 & 0 & 0 & 0 & 0 \\
\hline 12 & 2 & 0 & 0 & 0 & 0 & 0 \\
\hline 13 & 2 & 0 & 0 & 0 & 0 & 0 \\
\hline 14 & 2 & 0 & 0 & 0 & 0 & 0 \\
\hline 15 & 2 & 0 & 0 & 0 & 0 & 0 \\
\hline 16 & 3 & 1 & 1 & 33.3 & 0 & 0 \\
\hline 17 & 3 & 0 & 1 & 33.3 & 0 & 0 \\
\hline 18 & 8 & 5 & 1 & 12.5 & 0 & 0 \\
\hline 19 & 12 & 4 & 1 & 8.3 & 0 & 0 \\
\hline 20 & 12 & 0 & 1 & 8.3 & 0 & 0 \\
\hline 21 & 22 & 10 & 2 & 9.1 & 0 & 0 \\
\hline 22 & 24 & 2 & 2 & 8.3 & 0 & 0 \\
\hline 23 & 33 & 9 & 2 & 6.1 & 1 & 3 \\
\hline 24 & 44 & 10 & 2 & 4.1 & $\frac{1}{1}$ & 2.3 \\
\hline 25 & 51 & 7 & 2 & 3.9 & 1 & 2 \\
\hline 26 & 65 & 14 & 3 & 4.6 & 1 & 1.5 \\
\hline 27 & 65 & 0 & 3 & 4.6 & 1 & 1.5 \\
\hline 28 & 97 & 32 & 3 & 3.1 & 1 & 1 \\
\hline 29 & 111 & 14 & 3 & 2.7 & 1 & 0.9 \\
\hline 30 & 131 & 20 & 8 & 6.1 & 2 & 1.5 \\
\hline 31 & 139 & 8 & 9 & 6.5 & 2 & 1.4 \\
\hline
\end{tabular}

May 31, 2020, which show the epidemiological statistics of COVID-19/SARS-CoV-2 cases and discharge and death rates in Nigeria within the studied period.

Table 3 - April 2020 epidemiological statistics of COVID-19/SARS-CoV-2 cases in Nigeria

\begin{tabular}{|c|c|c|c|c|c|c|}
\hline Date & Total confirmed cases & Daily infections & Total discharged & $\%$ discharge & Total deaths & $\%$ deaths \\
\hline 1 & 174 & 35 & 9 & 5.2 & 2 & 1.1 \\
\hline 2 & 184 & 10 & 20 & 10.9 & 2 & 1.1 \\
\hline 3 & 210 & 26 & 25 & 11.9 & 4 & 1.9 \\
\hline 4 & 214 & 4 & 25 & 11.7 & 4 & 1.9 \\
\hline 5 & 232 & 18 & 33 & 14.2 & 5 & 1.5 \\
\hline 6 & 238 & 6 & 35 & 14.7 & 5 & 2.1 \\
\hline 7 & 254 & 16 & 44 & 17.3 & 6 & 2.4 \\
\hline 8 & 276 & 22 & 44 & 15.9 & 6 & 2.2 \\
\hline 9 & 288 & 12 & 51 & 17.7 & 7 & 2.4 \\
\hline 10 & 305 & 17 & 58 & 18.8 & 7 & 2.3 \\
\hline 11 & 318 & 13 & 70 & 22.0 & 10 & 3.1 \\
\hline 12 & 323 & 5 & 85 & 26.3 & 10 & 3.1 \\
\hline 13 & 343 & 20 & 91 & 26.5 & 10 & 2.9 \\
\hline
\end{tabular}




\begin{tabular}{|c|c|c|c|c|c|c|}
\hline Date & Total confirmed cases & Daily infections & Total discharged & \% discharge & Total deaths & $\%$ deaths \\
\hline 14 & 373 & 30 & 99 & 26.5 & 11 & 2.9 \\
\hline 15 & 407 & 34 & 128 & 31.4 & 12 & 2.9 \\
\hline 16 & 442 & 35 & 152 & 34.4 & 13 & 2.9 \\
\hline 17 & 493 & 51 & 159 & 32.3 & 17 & 3.4 \\
\hline 18 & 542 & 49 & 166 & 30.6 & 19 & 3.5 \\
\hline 19 & 627 & 85 & 170 & 27.1 & 21 & 3.3 \\
\hline 20 & 665 & 38 & 188 & 28.3 & 22 & 3.3 \\
\hline 21 & 782 & 117 & 197 & 25.2 & 25 & 3.2 \\
\hline 22 & 873 & 91 & 197 & 22.6 & 28 & 3.2 \\
\hline 23 & 981 & 108 & 197 & 20.1 & 31 & 3.2 \\
\hline 24 & 1097 & 116 & 208 & 19.0 & 32 & 2.9 \\
\hline 25 & 1182 & 85 & 222 & 18.8 & 35 & 3.0 \\
\hline 26 & 1273 & 91 & 239 & 18.8 & 40 & 3.1 \\
\hline 27 & 1337 & 64 & 255 & 19.1 & 40 & 3.0 \\
\hline 28 & 1532 & 195 & 255 & 16.6 & 44 & 2.9 \\
\hline 29 & 1728 & 196 & 307 & 17.8 & 51 & 3.0 \\
\hline 30 & 1932 & 204 & 319 & 16.5 & 58 & 3.0 \\
\hline
\end{tabular}

Table 4 - May 2020 epidemiological statistics of COVID-19/SARS-CoV-2 cases in Nigeria

\begin{tabular}{|c|c|c|c|c|c|c|}
\hline Date & Total confirmed cases & Daily infections & Total discharged & \% discharge & Total deaths & $\%$ deaths \\
\hline 1 & 2170 & 238 & 351 & 16.2 & 68 & 3.1 \\
\hline 2 & 2388 & 218 & 358 & 15.0 & 85 & 3.6 \\
\hline 3 & 2558 & 170 & 400 & 15.6 & 87 & 3.4 \\
\hline 4 & 2802 & 244 & 417 & 14.9 & 93 & 3.3 \\
\hline 5 & 2950 & 148 & 481 & 16.3 & 98 & 3.3 \\
\hline 6 & 3147 & 197 & 534 & 17.0 & 103 & 3.3 \\
\hline 7 & 3526 & 379 & 601 & 17.0 & 107 & 3.0 \\
\hline 8 & 3912 & 386 & 679 & 17.4 & 117 & 3.0 \\
\hline 9 & 4151 & 239 & 745 & 17.9 & 128 & 3.1 \\
\hline 10 & 4399 & 248 & 778 & 17.7 & 143 & 3.3 \\
\hline 11 & 4641 & 242 & 902 & 19.4 & 150 & 3.2 \\
\hline 12 & 4787 & 146 & 959 & 20.0 & 158 & 3.3 \\
\hline 13 & 4971 & 184 & 1070 & 21.5 & 164 & 3.3 \\
\hline 14 & 5162 & 193 & 1180 & 22.9 & 167 & 3.2 \\
\hline 15 & 5445 & 288 & 1320 & 24.2 & 171 & 3.1 \\
\hline 16 & 5621 & 176 & 1472 & 26.2 & 176 & 3.1 \\
\hline 17 & 5959 & 338 & 1594 & 26.7 & 182 & 3.1 \\
\hline 18 & 6175 & 216 & 1644 & 26.6 & 191 & 3.1 \\
\hline 19 & 6401 & 226 & 1734 & 27.1 & 192 & 3.0 \\
\hline 20 & 6677 & 284 & 1840 & 27.6 & 200 & 3.0 \\
\hline 21 & 7016 & 339 & 1907 & 27.2 & 211 & 3.0 \\
\hline 22 & 7261 & 245 & 2007 & 27.6 & 221 & 3.0 \\
\hline 23 & 7526 & 265 & 2174 & 28.9 & 221 & 2.9 \\
\hline 24 & 7839 & 313 & 2263 & 28.9 & 226 & 2.8 \\
\hline 25 & 8068 & 229 & 2311 & 28.6 & 233 & 2.9 \\
\hline 26 & 8344 & 276 & 2385 & 28.6 & 249 & 3.0 \\
\hline 27 & 8733 & 389 & 2501 & 28.6 & 254 & 2.9 \\
\hline 28 & 8915 & 182 & 2592 & 29.1 & 259 & 2.9 \\
\hline 29 & 9302 & 387 & 2697 & 29.0 & 261 & 2.8 \\
\hline 30 & 9855 & 553 & 2856 & 29.0 & 273 & 2.4 \\
\hline 31 & 10162 & 307 & 3007 & 29.6 & 287 & 2.8 \\
\hline & & & & & & \\
\hline
\end{tabular}




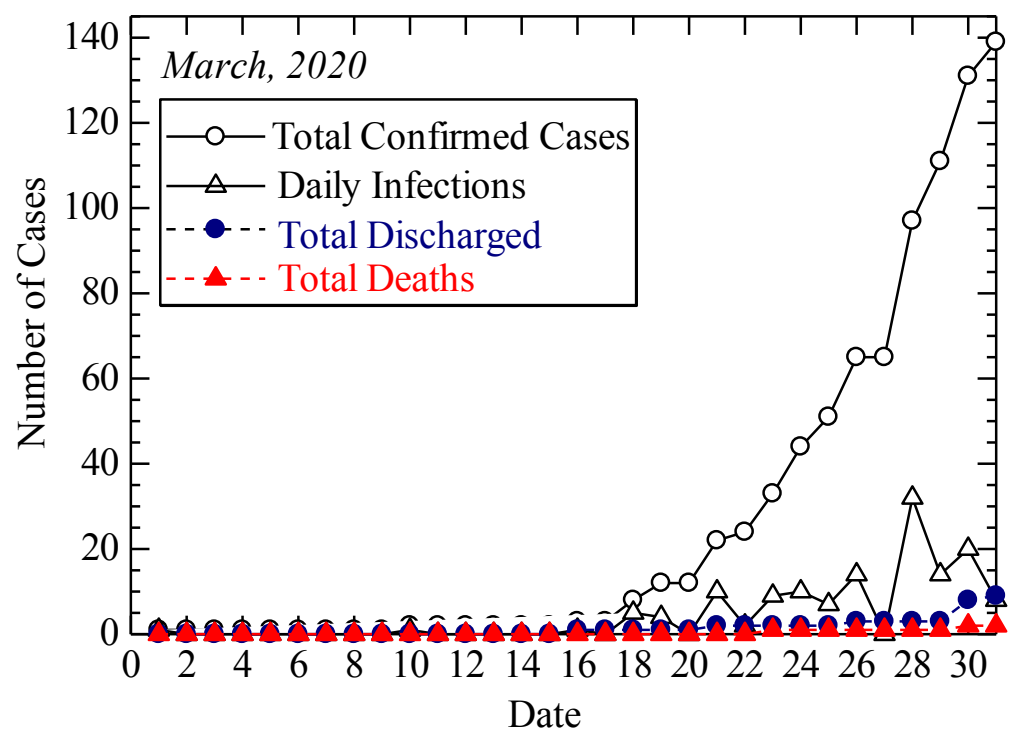

Figure 2 - March 2020 epidemiological timeline of COVID-19/SARS-CoV-2 spread in Nigeria

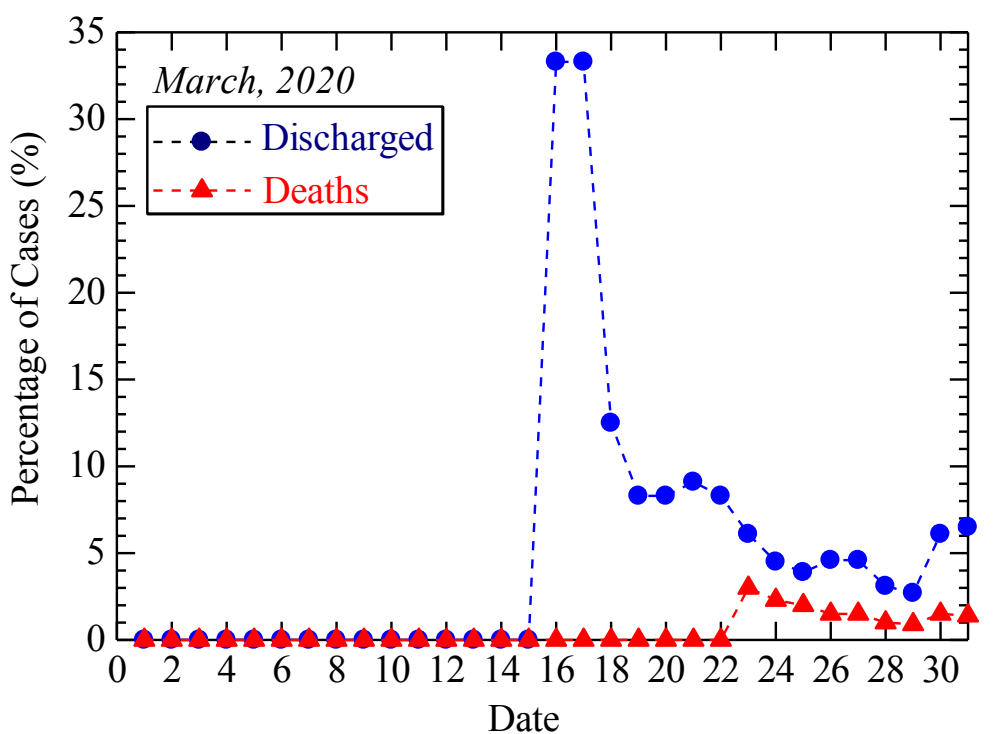

Figure 3 - March 2020 epidemiological timeline of COVID-19/SARS-CoV-2 discharge and deaths rates in Nigeria

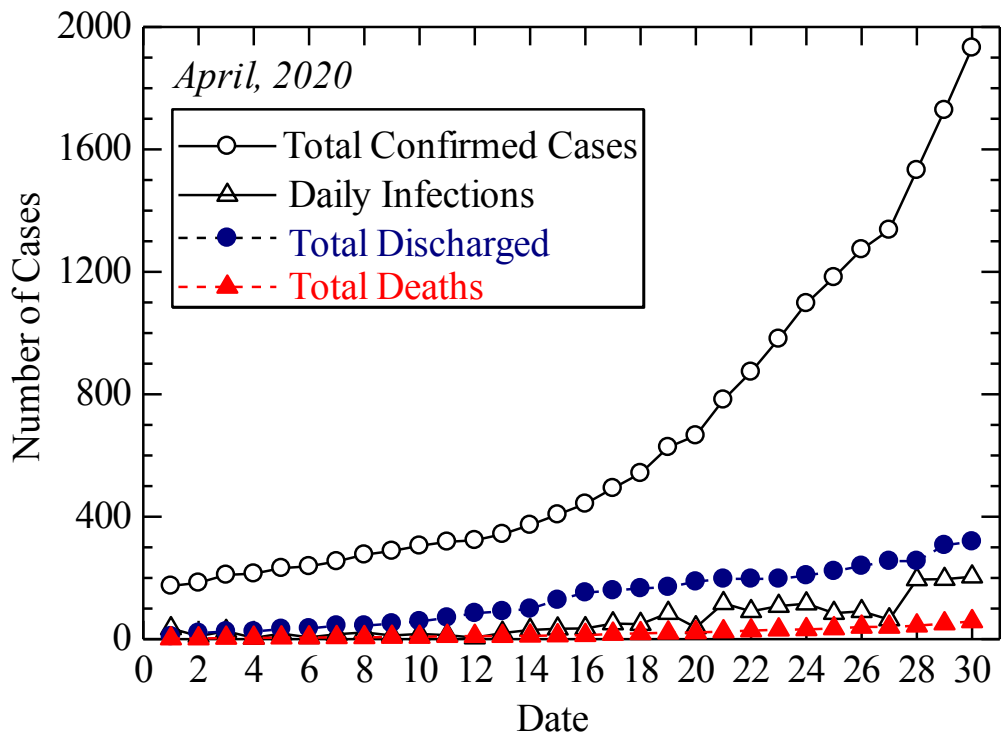

Figure 4 - April 2020 epidemiological timeline of COVID-19/SARS-CoV-2 spread in Nigeria 


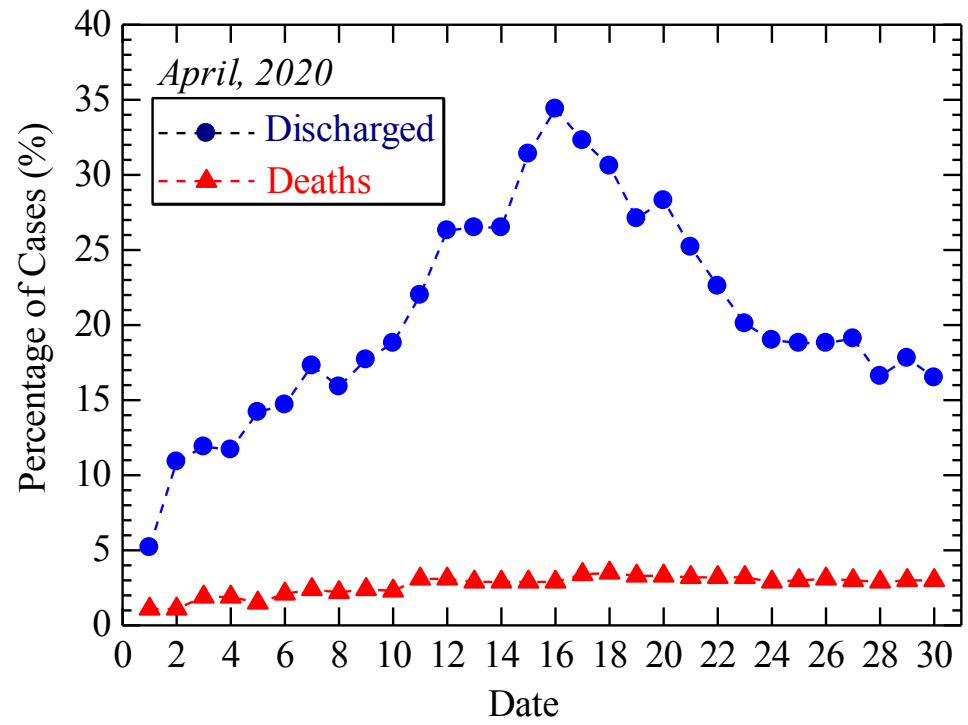

Figure 5 - April 2020 epidemiological timeline of COVID-19/SARS-CoV-2 discharge and death rates in Nigeria

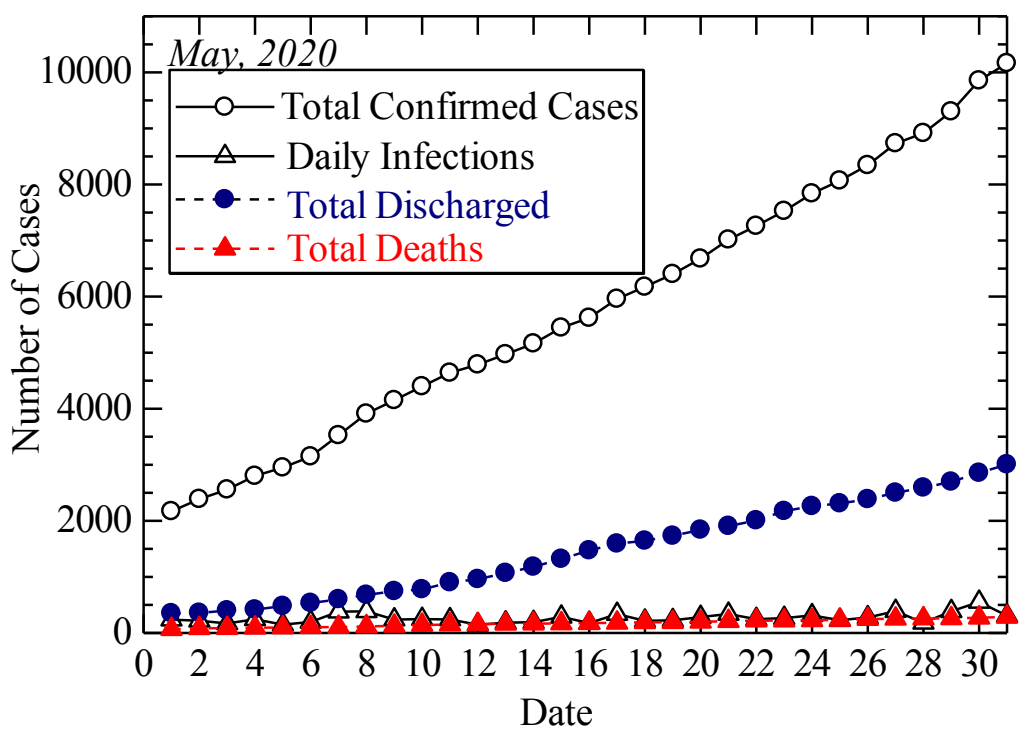

Figure 6 - May 2020 epidemiological timeline of COVID-19/SARS-CoV-2 spread in Nigeria

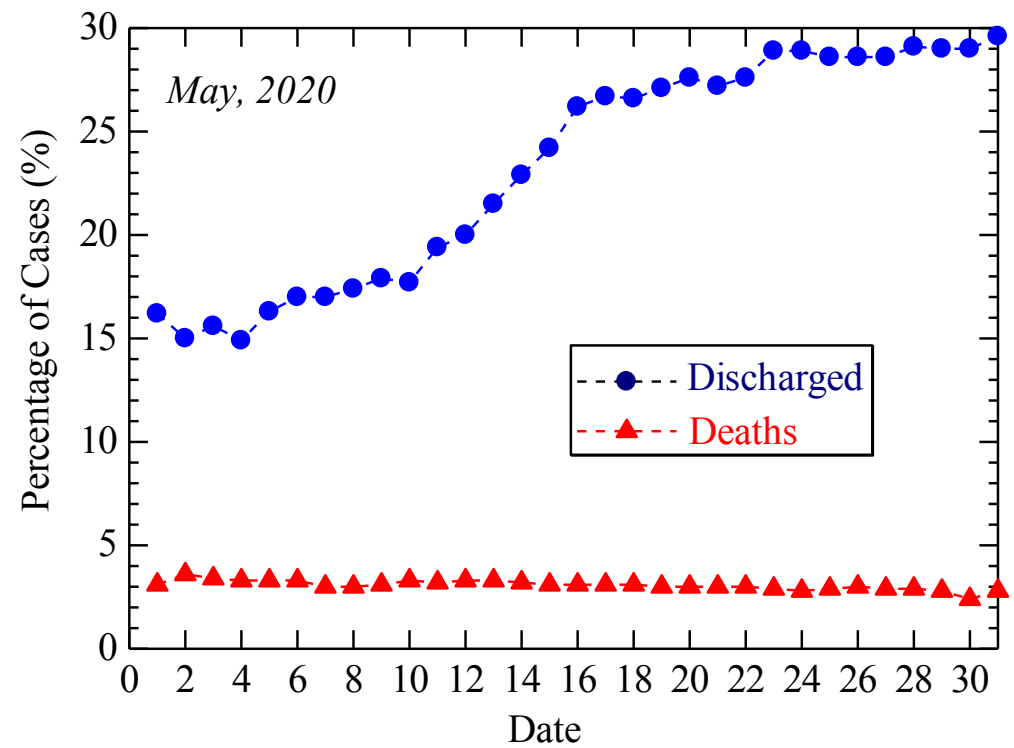

Figure 7 - May 2020 epidemiological timeline of COVID-19/SARS-CoV-2 discharge and deaths rates in Nigeria 
It can be shown from Table 2 and Figures 2-3 that the highest daily infection was recorded on the 28th of March with 32 infections while the highest fatality rate was recorded on March 24th with a rate of $2.3 \%$ and recorded daily infection of 10. As of March 31, 2020, a total number of 139 confirmed cases were recorded in Nigeria with a fatality and discharge rates of 1.4 and $6.5 \%$ respectively.

Table 3 and Figures 4-5 present the studied cases for April 2020. It can be deduced that the highest daily infection in Nigeria in April was recorded on April 30, 2020, with daily infection of 204 confirmed cases. The highest discharge rate of $34.4 \%$ was recorded on April 16, with a fatality rate of $2.9 \%$ while the highest fatality rate of April was $3.5 \%$ recorded on April 18, 2020, which has a discharge rate of $30.6 \%$ and a daily infection record of 49. As of April 30, 2020, Nigeria had recorded a total of 1932 confirmed cases with 58 deaths.

Table 4 and Figures 6-7 present the studied cases for May 2020. It can be deduced that the highest daily infection in Nigeria in May was recorded on May 30, 2020, with daily infection of 553 confirmed cases. It can also be observed that the highest discharge and fatality rates for May 2020 are 29.6\% and 3.6\% recorded on May 31, 2020, and May 2, 2020, respectively. As of May 31,2020 , the total infection stood at 10162 confirmed cases and there seems to be a continuing upward trajectory for the situation under investigation. From Figures 3, 5, 7, it can be observed that the rate of discharged cases continued to surpass those of the fatality for the months of investigation.

Epicentres/severely affected states of the epidemiological spread of COVID-19/SARS-CoV-2 in Nigeria in May 2020. Table 5 and Figures 8-9 represent the epidemiological timeline of COVID19/SARS-CoV-2 spread in the most affected states (epicentres) in Nigeria for May 2020, which show the epidemiological statistics of COVID-19/SARS-CoV-2 daily infections within the studied period.

Table 5 - May 2020 epidemiological statistics of COVID-19/SARS-CoV-2 cases in 10 most severely affected states in Nigeria

\begin{tabular}{|c|c|c|c|c|c|c|c|c|c|c|}
\hline Date & Lagos & Kano & FCT & Katsina & Bauchi & Borno & Ogun & Oyo & Jigawa & Kaduna \\
\hline 1 & 30 & 52 & 36 & - & 10 & 3 & - & 6 & - & - \\
\hline 2 & 62 & 7 & 52 & - & 5 & 6 & - & 4 & - & 31 \\
\hline 3 & 39 & 29 & 12 & 8 & 18 & 7 & 24 & 1 & - & 15 \\
\hline 4 & 76 & 23 & 19 & 37 & 9 & 18 & 5 & 5 & 32 & - \\
\hline 5 & 43 & 32 & 10 & 9 & 3 & 6 & 6 & 5 & - & 3 \\
\hline 6 & 82 & 30 & 9 & 3 & - & 10 & 4 & 8 & - & 1 \\
\hline 7 & 183 & 55 & - & 11 & 19 & 9 & 5 & 3 & 44 & 7 \\
\hline 8 & 176 & 63 & 20 & 31 & 15 & 17 & 13 & 4 & - & 3 \\
\hline 9 & 97 & 29 & 7 & 19 & 44 & 17 & 2 & 5 & - & 3 \\
\hline 10 & 81 & 26 & 13 & - & 20 & 26 & 2 & - & 35 & - \\
\hline 11 & 88 & 64 & 3 & 49 & 1 & 1 & 9 & 1 & - & 13 \\
\hline 12 & 57 & 27 & 1 & 3 & 8 & 2 & 1 & 4 & - & - \\
\hline 13 & 51 & 14 & 10 & 16 & 16 & - & - & 4 & 23 & 5 \\
\hline 14 & 58 & 46 & 9 & - & 1 & 3 & 7 & - & 35 & - \\
\hline 15 & 179 & 8 & 7 & 15 & 3 & 13 & 11 & 13 & 15 & 20 \\
\hline 16 & 95 & - & 11 & - & 2 & 8 & - & 12 & 6 & - \\
\hline 17 & 177 & 64 & 21 & 9 & 3 & 3 & - & 11 & 4 & 4 \\
\hline 18 & 74 & 17 & 4 & 33 & 7 & 8 & 8 & 19 & - & 3 \\
\hline 19 & 131 & - & 5 & - & 2 & 4 & 25 & 6 & 4 & 7 \\
\hline 20 & 199 & 5 & 8 & - & - & 8 & - & 19 & 6 & - \\
\hline 21 & 139 & 28 & 11 & 22 & 4 & - & 5 & 28 & 14 & 18 \\
\hline 22 & 132 & 8 & 1 & 5 & - & 12 & 13 & 9 & 16 & 9 \\
\hline 23 & 133 & - & 22 & - & 2 & 3 & 23 & 34 & - & 5 \\
\hline 24 & 148 & 13 & 36 & - & - & - & 12 & 7 & - & 5 \\
\hline 25 & 90 & 23 & 14 & 27 & - & 5 & 9 & 4 & - & - \\
\hline 26 & 161 & 4 & - & - & 1 & - & - & - & - & 19 \\
\hline
\end{tabular}




\begin{tabular}{|c|c|c|c|c|c|c|c|c|c|c|}
\hline Date & Lagos & Kano & FCT & Katsina & Bauchi & Borno & Ogun & Oyo & Jigawa & Kaduna \\
\hline 27 & 256 & 13 & - & 23 & - & 1 & 1 & 2 & - & 7 \\
\hline 28 & 111 & 3 & 16 & - & 1 & 1 & 4 & 8 & - & 6 \\
\hline 29 & 254 & 3 & 29 & - & 2 & 6 & - & 15 & 24 & 11 \\
\hline 30 & 378 & 9 & 52 & 6 & - & 7 & 13 & 5 & 5 & 12 \\
\hline 31 & 188 & 3 & 44 & - & 2 & - & 19 & 12 & - & 14 \\
\hline
\end{tabular}

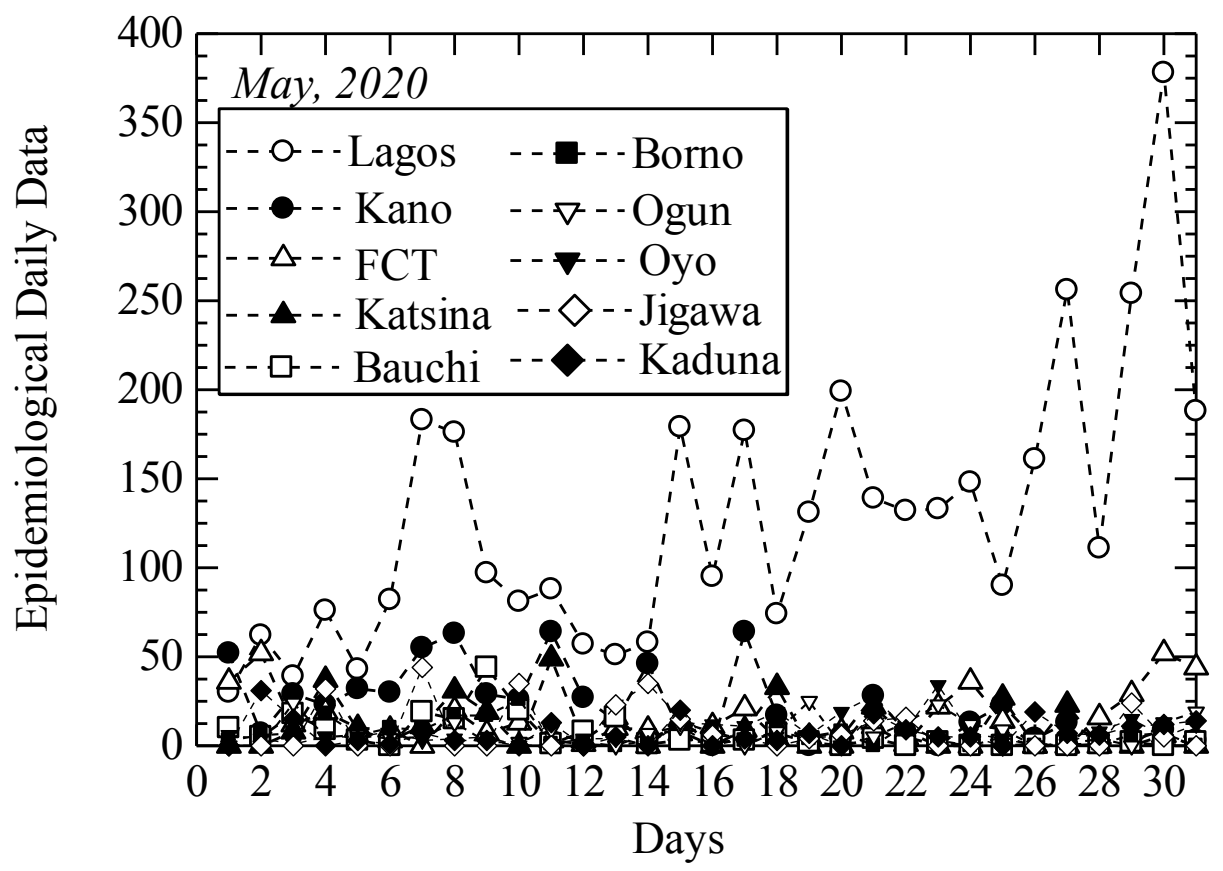

Figure 8 - May 2020 epidemiological statistics of COVID-19/SARS-CoV-2 cases in 10 most severely affected states in Nigeria

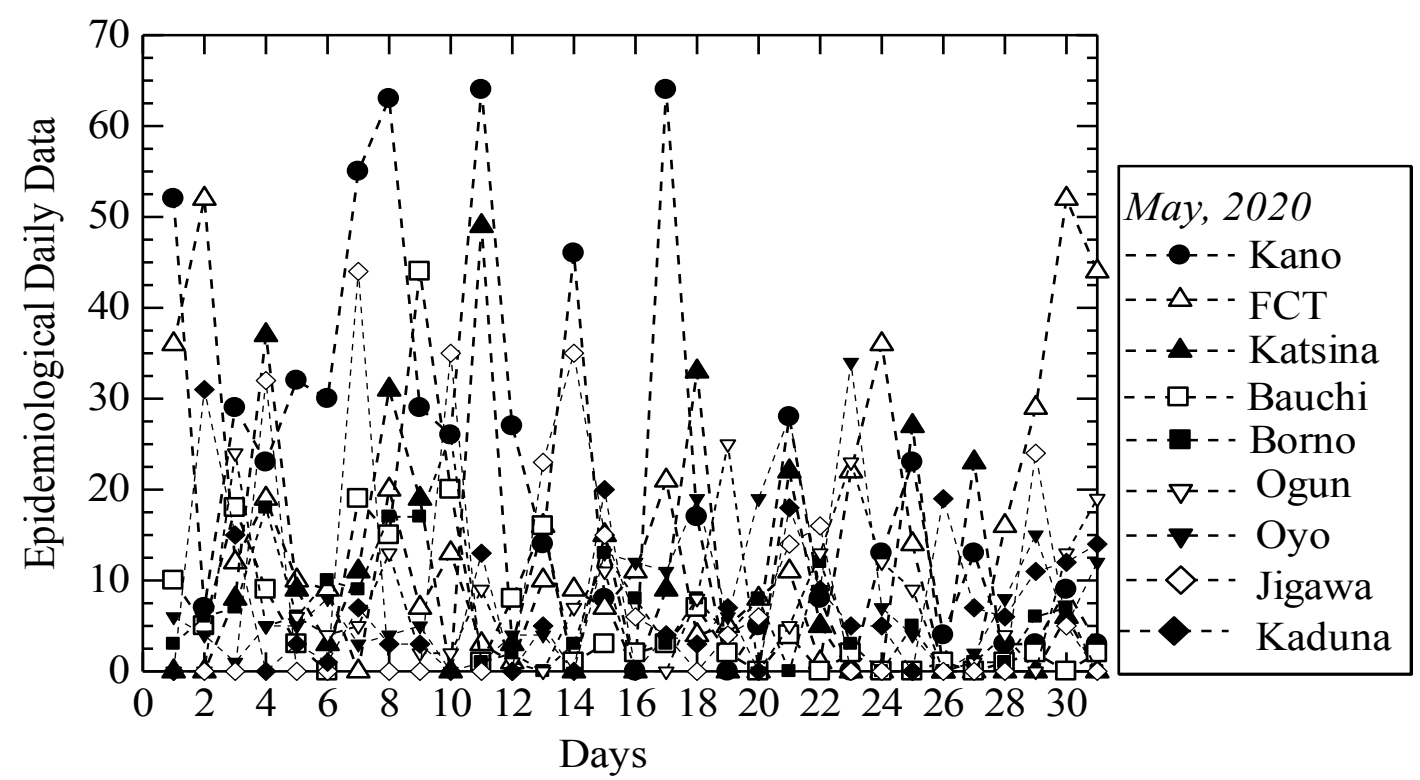

Figure 9 - May 2020 epidemiological statistics of COVID-19/SARS-CoV-2 cases in 10 most severely affected states in Nigeria without Lagos

No doubts that the COVID-19/SARS-CoV-2 was first recorded in the Ogun State of Nigeria, but Lagos state has surpassed both the daily infections and the cumulative infections for the country. On May 30, 2020, Lagos state recorded a daily total of 378 confirmed cases as shown in Table 4 and Fig. 8. Kano state had continued to follow in the rate at which cases are confirmed in Nigeria and followed by the other 8 states as shown in Table 5. 
Analysis of Variance Result (ANOVA). The data sets were statistically analyzed using ANOVA; the experimental duration, daily infections and percentage discharge are the predictor variables while the total discharged, total deaths and total confirmed cases are the target variables of the regression in the ANOVA, model-independent variables were assessed to the three response or outcome variables as shown in Tables 6-8.

Table 6 - Analysis of Variance for Total Discharged Response

\begin{tabular}{|l|c|c|c|c|c|}
\hline \multicolumn{1}{|c|}{ Source } & DF & Adj SS & Adj MS & F-Value & P-Value \\
\hline Regression & 3 & 45505763 & 15168588 & 77.78 & 0.000 \\
\hline Duration & 1 & 875631 & 875631 & 4.49 & 0.037 \\
\hline Daily infections & 1 & 3474712 & 3474712 & 17.82 & 0.000 \\
\hline \% discharge & 1 & 55333 & 55333 & 0.28 & 0.596 \\
\hline Error & 88 & 17162226 & 195025 & & \\
\hline Total & 91 & 62667989 & & & \\
\hline
\end{tabular}

Table 7 - Analysis of Variance for Total Deaths Response

\begin{tabular}{|l|c|c|c|c|c|}
\hline \multicolumn{1}{|c|}{ Source } & DF & Adj SS & Adj MS & F-Value & P-Value \\
\hline Regression & 3 & 588680 & 196227 & 149.60 & 0.000 \\
\hline Duration & 1 & 23005 & 23005 & 17.54 & 0.000 \\
\hline Daily infections & 1 & 34200 & 34200 & 26.07 & 0.000 \\
\hline \% discharge & 1 & 997 & 997 & 0.76 & 0.386 \\
\hline Error & 88 & 115430 & 1312 & & \\
\hline Total & 91 & 704110 & & & \\
\hline
\end{tabular}

Table 8 - Analysis of Variance for Total Confirmed Cases Response

\begin{tabular}{|l|c|c|c|c|c|}
\hline \multicolumn{1}{|c|}{ Source } & DF & Adj SS & Adj MS & F-Value & P-Value \\
\hline Regression & 3 & 659902403 & 219967468 & 137.12 & 0.000 \\
\hline Duration & 1 & 20641294 & 20641294 & 12.87 & 0.001 \\
\hline Daily infections & 1 & 44711208 & 44711208 & 27.87 & 0.000 \\
\hline \% discharge & 1 & 467384 & 467384 & 0.29 & 0.591 \\
\hline Error & 88 & 141168026 & 1604182 & & \\
\hline Total & 91 & 801070429 & & & \\
\hline
\end{tabular}

The indices used for the statistical analysis are adjusted sum of square adjusted mean squares and P-value. The adjusted mean square helps to evaluate the variation of a model or system that predicts its response. It considers the degree of freedom and provides a platform for the computation of the adjusted coefficient of determination statistics ( $\mathrm{R}^{2}$-adj) presented in the model summary. The adjusted sum of squares helps to assess the various measures of different model parameters without taking into account the order of the independent variables of the model. It is also utilized for the computation of the p-value of the factor levels and also the coefficient of the determination statistics $\left(\mathrm{R}^{2}\right)$; this is used together with the computed $\mathrm{p}$-value for interpretation of model performance.

The P-value provides the criteria for a rating of statistical significance within a hypothesis testing which shows where enough evidence exists for the acceptance or rejection of the conjecture or null hypothesis. For results interpretation, if $\mathrm{P}$ value $>\alpha$ then we accept the null hypothesis which means that the corresponding factor is not an important predictor and possesses negligible value within the model but if $\mathrm{P}$-value $>\alpha$ then we accept the alternate hypothesis which means that they are statistically significant to the prediction of the response parameter.

From the computed results, \% discharge factor has a p-value of $0.596,0.386$ and 0.591 for the three target responses respectively which indicated that the \% discharge factor is not significant while the other factors; \% confirmed and \% deaths, in the predictor variables are statistically significant. 
The Model Summary and Regression Coefficients. The developed regression model performance rating parameters are presented in the model summary for the derivation of the coefficient of determination $\left(R^{2}\right)$ which is the variation (in percentage) in the outcome explained by the MLR model. It is used to determine how well the model fits the system database; the higher the values, the better the model performance and its results range from a minimum of $0 \%$ to maximum of $100 \%$ signifying that the fitted values are equal to the observed value.

Regression Equation. The regression equation helps to express the relationship between the dependent variable or model response and independent variables; it is expressed in the algebraic form of a regression line which takes the form of:

$$
y=\beta_{0}+\beta_{1} x_{1}+\ldots+\beta_{n} x_{n}
$$

where $y$ is the dependent or target variables, $\beta_{0}$ is the constant term, $\beta_{1}, \beta_{2}, \ldots \beta_{n}$ is the regression coefficients and $x_{1}, x_{2}, \ldots x_{n}$ is the independent or predictor variables.

The model parameters are presented in Table 9.

Table 9 - MLR Model Parameters

\begin{tabular}{|l|c|c|c|c|c|c|c|c|}
\hline \multicolumn{4}{|c|}{ Model Summary } & \multicolumn{4}{c|}{ Coefficients of Regression } \\
\hline Response Parameters & $\mathrm{S}$ & $\mathrm{R}^{2}(\%)$ & $\mathrm{R}^{2}$-Pred (\%) & $\mathrm{R}^{2}$-adj (\%) & Constant & Duration & Daily infections & $\%$ discharge \\
\hline Total discharged & 441.617 & 72.61 & 69.55 & 71.68 & -369 & 10.42 & 3.287 & 3.88 \\
\hline Total deaths & 36.2174 & 83.61 & 81.81 & 83.05 & -40.19 & 1.688 & 0.3261 & -0.521 \\
\hline Total confirmed cases & 1266.56 & 82.38 & 80.44 & 81.78 & -1284 & 50.6 & 11.79 & -11.3 \\
\hline
\end{tabular}

The regression equations are presented in Formulas 4- 6 for the three target parameters as follows:

$$
\begin{gathered}
\text { TDs }=-369+10.42 D+3.287 D I+3.88 P D \\
T D t=-40.19+1.688 D+0.3261 D I-0.521 P D(5) \\
T C C=-1284+50.6 D+11.79 D I-11.3 P D
\end{gathered}
$$

Where TDs is total discharge, TDt is total deaths, TCC is total confirmed cases, D is duration period, DI is daily infections, and PD is percentage discharge

Residual Plot. The residual plots show the residual values on the $y$-axis against the independent variable on the $\mathrm{x}$-axis. The model residual results are obtained from the formula 7 :

$$
\text { residual }=\text { observed }- \text { predicted }
$$

Since linear regression models are not always appropriate in terms of prediction performance, the evaluation of the appropriateness of the model is achieved by defining and examining the residual plots shown in Figures 10-12.

The plots present the behavioural curves and Histogram charts of residuals which determine the skewness of the data under statistical examination; the normal probability plot of residuals which helps to verify the assumptions that residuals are normally distributed, the residual vs fit plot helps to verify that the residuals possess constant variance and residual versus the order of data which helps to verify that the residuals are uncorrelated with each other.

\section{CONCLUSIONS}

From the foregoing epidemiological analysis and time prediction models of coronavirus (COVID19/SARS-CoV-2) spread in selected epicentres around the world with a focus on Nigeria case, it can be concluded with the following remarks.

1. That the data of total confirmed cases, daily infections, daily discharge case, daily deaths, percentage discharge and deaths were successfully collected for three months through releases from the Nigeria Centre for Disease Control (NCDC).

2. That the collected data were analysed and results presented in graphs to show the behaviour of the virus spread within the period under investigation. 


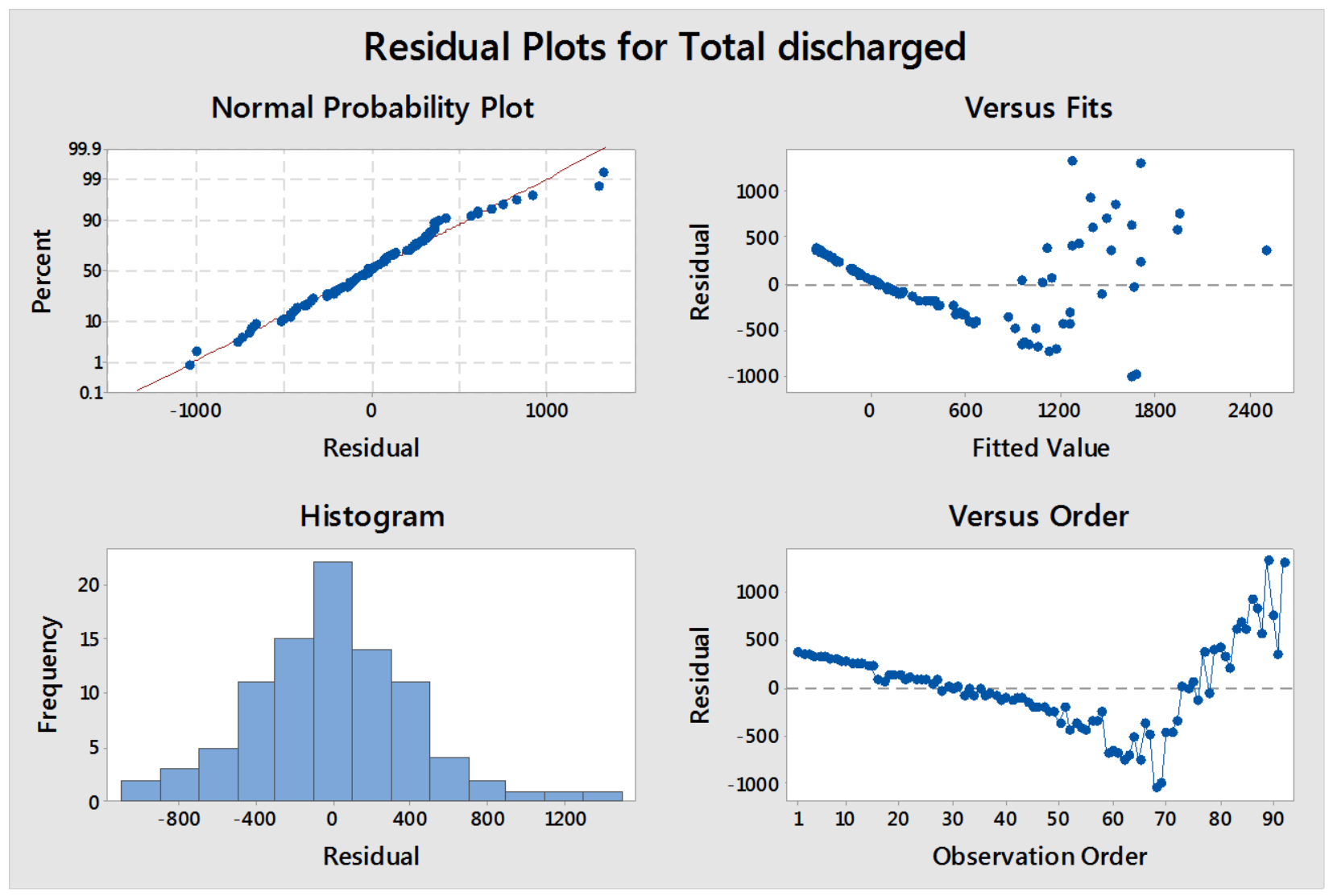

Figure 10 - Residual Plots for Total discharged

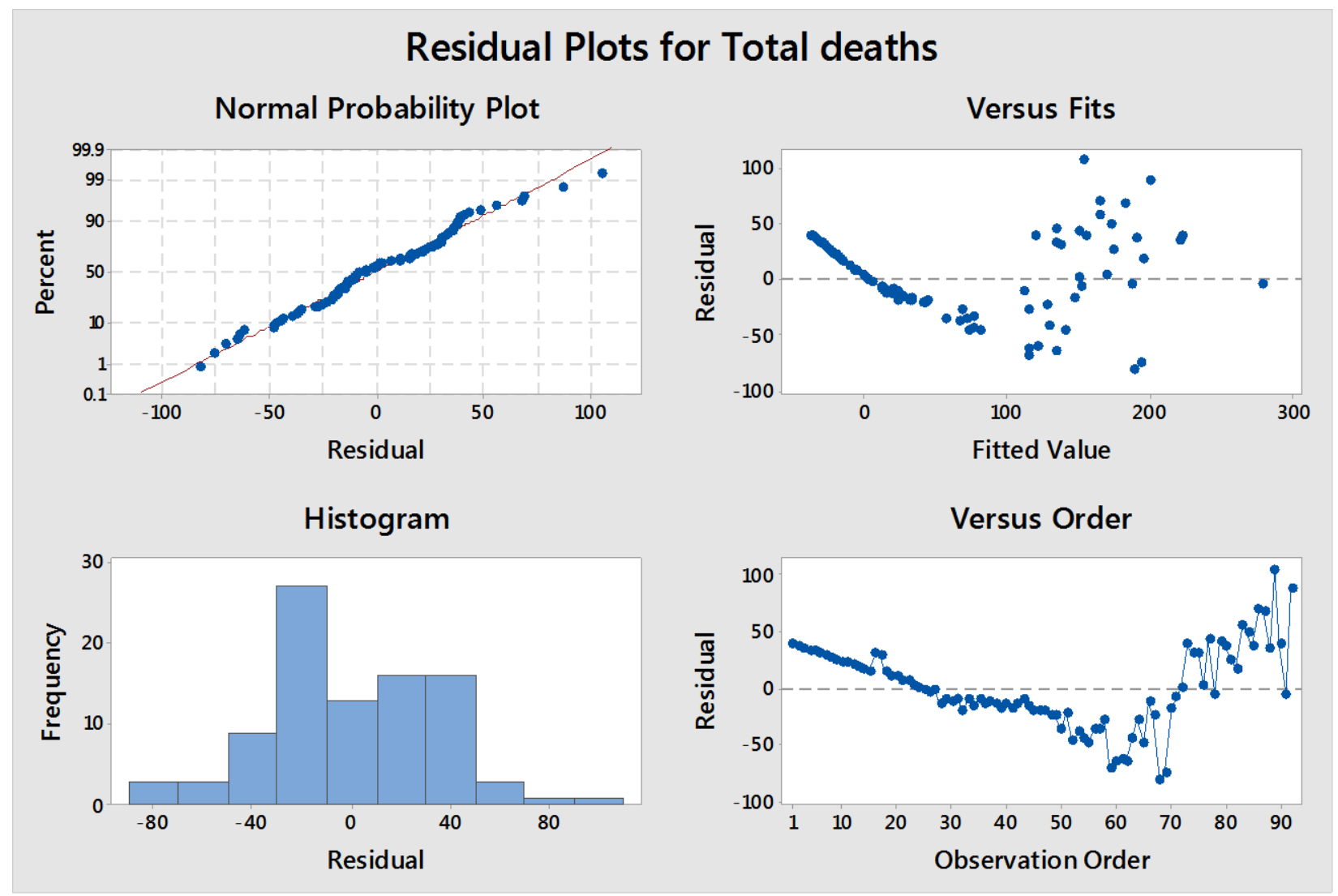

Figure 11 - Residual Plots for Total deaths 


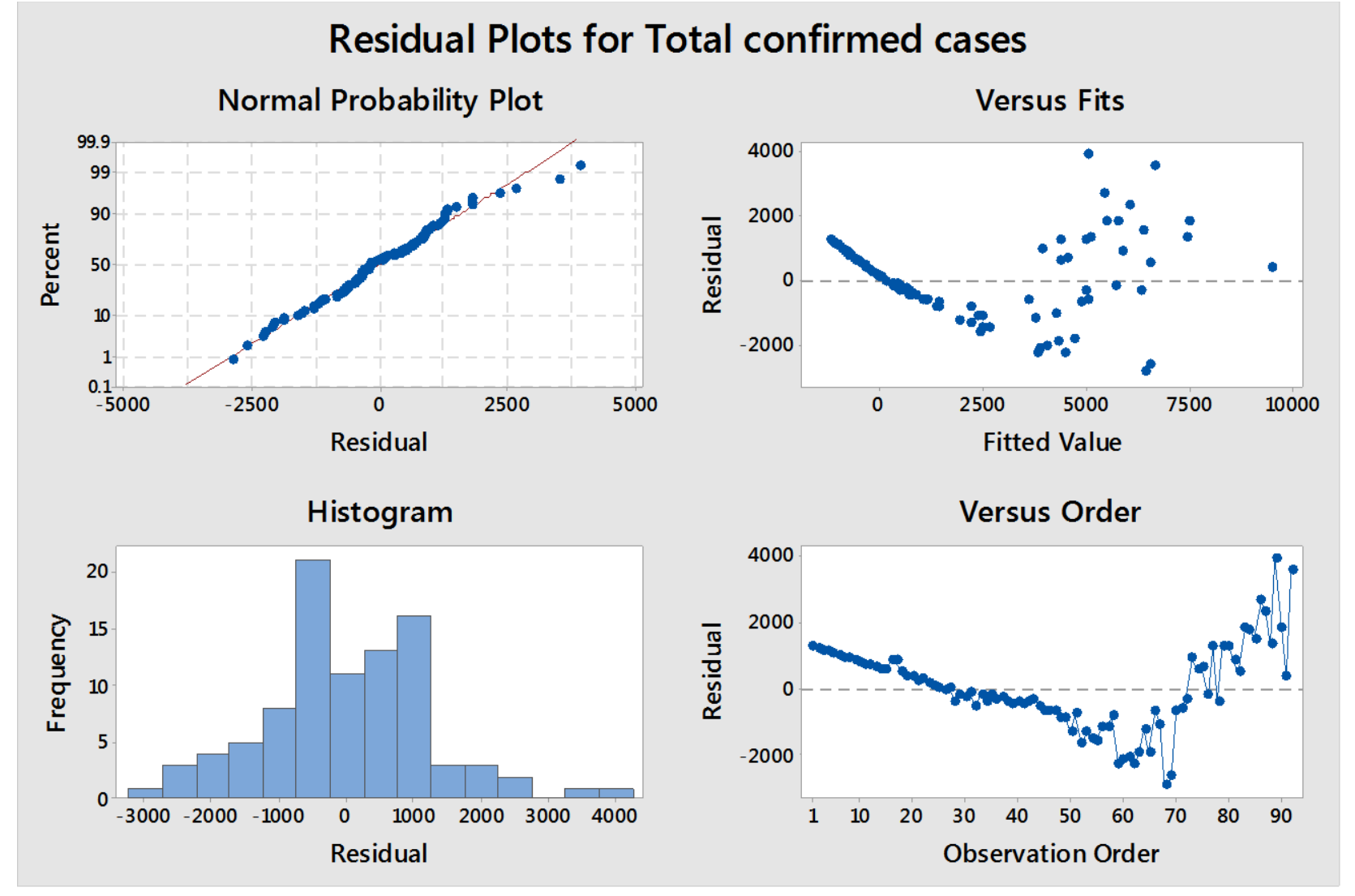

Figure 12 - Residual Plots for Total confirmed cases

\section{CONCLUSIONS (CONTINUOUS)}

3. That a time prediction model was conducted using the MLR and ANOVA algorithms to predict what would be the behaviour of the virus spread in Nigeria in any period and the regression equations were proposed.
That the proposed equations were validated as to established the functions that are more relevant to affect the results of the future predictions and this showed that total confirmed cases and total deaths are the independent variables that showed more effect on the suggested model expressions.

\section{REFERENCES}

1. Adhikari, S. P., Meng, S., Wu, Y.-J., Mao, Y.-P., Ye, R.-X., Wang, Q.-Z., ... Zhou, H. (2020). Epidemiology, causes, clinical manifestation and diagnosis, prevention and control of coronavirus disease (COVID-19) during the early outbreak period: a scoping review. Infectious Diseases of Poverty, 9(1). doi: 10.1186/s40249-020-00646-x

2. Beeching, N., Fletcher, T., Fowler, R. (2020). Coronavirus disease 2019 (COVID-19). Retrieved from https://bestpractice.bmj.com/topics/en-gb/3000168

3. Chen, N., Zhou, M., Dong, X., Qu, J., Gong, F., Han, Y., ... Zhang, L. (2020). Epidemiological and clinical characteristics of 99 cases of 2019 novel coronavirus pneumonia in Wuhan, China: a descriptive study. The Lancet, 395(10223), 507-513. doi: 10.1016/s0140-6736(20)30211-7

4. Di Gennaro, F., Pizzol, D., Marotta, C., Antunes, M., Racalbuto, V., Veronese, N., \& Smith, L. (2020). Coronavirus Diseases (COVID-19) Current Status and Future Perspectives: A Narrative Review. International Journal of Environmental Research and Public Health, 17(8), 2690. doi: 10.3390/ijerph17082690

5. Epidemiology Working Group for NCIP Epidemic Response, Chinese Center for Disease Control and Prevention (2020). Zhonghua liu xing bing xue za zhi = Zhonghua liuxingbingxue zazhi, 41(2), 145-151. Retrieved from https://doi.org/10.3760/cma.j.issn.0254-6450.2020.02.003 
6. Government of Canada. (2020). Coronavirus disease 2019 (COVID-19): Epidemiology Update. Retrieved from July 20, 2020, from https://health-infobase.canada.ca/covid19/epidemiological-summary-covid-19-cases.html

7. Guo, Y.-R., Cao, Q.-D., Hong, Z.-S., Tan, Y.-Y., Chen, S.-D., Jin, H.-J., ... Yan, Y. (2020). The origin, transmission and clinical therapies on coronavirus disease 2019 (COVID-19) outbreak - an update on the status. Military Medical Research, 7(1). doi: 10.1186/s40779-020-00240-0

8. Isaacs, D., Flowers, D., Clarke, J. R., Valman, H. B., \& MacNaughton, M. R. (1983). Epidemiology of coronavirus respiratory infections. Archives of Disease in Childhood, 58(7), 500-503. doi: 10.1136/adc.58.7.500

9. Lu, R., Zhao, X., Li, J., Niu, P., Yang, B., Wu, H., ... Tan, W. (2020). Genomic characterisation and epidemiology of 2019 novel coronavirus: implications for virus origins and receptor binding. The Lancet, 395(10224), 565-574. doi: 10.1016/s0140-6736(20)30251-8

10. Ma, S., Zhang, J., Zeng, M., Yun, Q., Guo, W., Zheng, Y., ... Yang, Z. (2020). Epidemiological parameters of coronavirus disease 2019: a pooled analysis of publicly reported individual data of 1155 cases from seven countries. doi: 10.1101/2020.03.21.20040329

11. Rothan, H. A., \& Byrareddy, S. N. (2020). The epidemiology and pathogenesis of coronavirus disease (COVID-19) outbreak. Journal of Autoimmunity, 109, 102433. doi: 10.1016/j.jaut.2020.102433

12. Sohrabi, C., Alsafi, Z., O’Neill, N., Khan, M., Kerwan, A., Al-Jabir, A., ... Agha, R. (2020). World Health Organization declares global emergency: A review of the 2019 novel coronavirus (COVID-19). International Journal of Surgery, 76, 71-76. doi: 10.1016/j.ijsu.2020.02.034

13. Steffens, I. (2020). A hundred days into the coronavirus disease (COVID-19) pandemic. Eurosurveillance, 25(14). doi: 10.2807/1560-7917.es.2020.25.14.2000550

14. Sun, K., Chen, J., \& Viboud, C. (2020). Early epidemiological analysis of the coronavirus disease 2019 outbreak based on crowdsourced data: a population-level observational study. The Lancet Digital Health, 2(4), e201-e208. doi: 10.1016/s2589-7500(20)30026-1

15. Verity, R., Okell, L. C., Dorigatti, I., Winskill, P., Whittaker, C., Imai, N., ... Ferguson, N. M. (2020). Estimates of the severity of coronavirus disease 2019: a model-based analysis. The Lancet Infectious Diseases, 20(6), 669-677. doi: 10.1016/s1473-3099(20)30243-7 